\title{
Mediação de Conflitos na Área da Saúde: experiência portuguesa e brasileira
}

\author{
Conflict Mediation in Health Area: Portuguese and Brazilian experience
}

Mediación de conflictos en la salud: experiencia portuguesa y brasileña

\section{Dulce Nascimento ${ }^{1}$}

RESUMO: A área da Saúde representa um direito constitucionalmente reconhecido, na maioria dos países, designadamente atendendo à sua importância humana e social. Reconhecido como um direito fundamental, possui uma natureza complexa devido à multiplicidade de elementos que o caracterizam, incluindo sociais, subjetivos e culturais. Contudo, como é sabido, a sua efetivação depende de políticas públicas e investimentos privados, quer estejamos a falar de saúde pública ou privada, adequadas à efetiva satisfação de necessidades básicas dos indivíduos. Tendo em consideração o seu reconhecimento constitucional importa questionar como se encontra, na atualidade, o efetivo acesso à saúde e quais os meios mais adequados para resolver os mais diversificados conflitos existentes nesta área jurídica do direito. $O$ artigo procura compartilhar a necessária e imprescindível reflexão, com origem na experiência prática, sobre a possibilidade de através da Mediação de conflitos responder à dificuldade de encontrar através dos meios tradicionais de resolução de conflitos, resposta efetiva a alguns interesses e necessidades inerentes às múltiplas e diversificadas relações que se criam no âmbito médico, clínico e hospitalar. Ou seja, respostas com soluções globais e definitivas, em decorrência da prestação de serviços na área da saúde.

Palavras-chave: Mediação. Conflito. Saúde. Advocacia Colaborativa. Portugal e Brasil.

ABSTRACT: The Health area is a constitutionally recognized right in most countries, particularly in view of its human and social importance. Recognized as a fundamental right, it has a complex nature because the multiplicity of elements that characterize it, including social, cultural and subjective. However, as is known, its effectiveness depends on public and private investment policies, whether we are talking about public or private health, adequate for the effective provision of basic needs of individuals. Taking into account its constitutional recognition important question as it stands at present, effective access to health and what the most appropriate means to address the most diverse legal conflicts in this area of law. The article wants to share the necessary and indispensable reflection, originating from the practical experience of the possibility of through the mediation of conflicts respond to the difficulty of finding through traditional means of conflict resolution,

\footnotetext{
${ }^{1}$ Dulce Maria Martins do Nascimento - Mediadora Certificada: IMI - International Mediation Institute (2015); ICFML - Instituto de Certificação e Formação de Mediadores Lusófonos (2014); CPR - International Institute for Conflict Prevention \& Resolution (2013) e IMAP - Instituto de Mediação e Arbitragem de Portugal (2002). Mestre em Direito (2014). Advogada Colaborativa - Portugal e Brasil (OAP e OABMG). Professora Convidada Especialista em MARL (2013). Coordenadora da Mediação, Conciliação e Arbitragem na ESA-OABMG (2016). Membro da Comissão Nacional de Mediação e Conciliação do CFOAB (2016). Juíza Coordenadora do Julgado de Paz de Santa Maria da Feira (2008-2013). Mediadora de Conflitos (2002). Jurista e Assessora de Administração (1997). dulcemnascimento@gmail.com.
} 
effective response to some concerns and needs to the multiple and diverse relationships that are created with medical, clinical and hospital. The responses to global and definitive solutions, for the provision of services in health care.

Keywords: Mediation. Conflict. Health. Collaborative law. Portugal and Brazil.

RESUMEN: El área de salud es un derecho constitucionalmente reconocido en la mayoría de los países, sobre todo en vista de su importancia humana y social. Reconocida como un derecho fundamental, que tiene una naturaleza compleja debido a la multiplicidad de elementos que lo caracterizan, incluyendo social, cultural y subjetiva. Sin embargo, como es sabido, su eficacia depende de las políticas de inversión pública y privada, si estamos hablando de la salud pública o privada, adecuada para la prestación eficaz de las necesidades básicas de las personas. Teniendo en cuenta su reconocimiento constitucional cuestión importante, ya que, en el estado actual, el acceso efectivo a la salud y cuáles son los medios más adecuados para hacer frente a los más diversos conflictos legales en esta área del derecho. El artículo trata de compartir la reflexión necesaria e indispensable, procedente de la experiencia práctica de la posibilidad de que a través de la mediación de conflictos responder a la dificultad de encontrar a través de los medios tradicionales de resolución de conflictos, respuesta eficaz a algunas de las preocupaciones y las necesidades inherentes a la múltiple y diversas relaciones que se crean dentro médica, clínica y hospitalaria. es decir, las respuestas a las soluciones globales y definitivas, debido a la provisión de servicios de atención de la salud.

Palabras-Ilave: Mediación. Conflicto. Salud. Ley De Colaboración. Portugal y Brasil.

\section{Introdução}

Abordar o tema da Mediação, como método de resolução de conflitos adequado, impõe previamente ter de falar sobre conflito, incluindo qual o seu significado, como o mesmo é definido pelos sujeitos, quais os elementos que o identificam, e em particular quais as particularidades e contexto que encontramos nos conflitos na área da saúde.

De uma forma consensual e empírica, o ser humano considera o conflito como algo desagradável ou mesmo ruim, que deve ser evitado. No âmbito dos recursos humanos, em especial no mundo empresarial, veio a verificar-se uma alteração na forma como definimos o conflito. Assim, na década de 30, caracterizada por escola unitária, com uma perspectiva tradicional, o conflito era visto como disfuncional, ou seja, algo negativo, que deveria de ser evitado a todo o custo. Neste sentido, esta escola defendia que surgindo o conflito deveria de ser eliminado, de imediato, pela autoridade e poder, sendo a inexistência de conflitos vista como um elemento de competência.

Mais tarde, durante as décadas de 40-70 do século passado, verificou-se uma evolução na escola das relações humanas, tendo-se passado a defender uma perspectiva 
pluralista, no sentido de visualizar o conflito como um fenômeno inevitável nas relações entre seres humanos, que pode inclusive ser benéfico atendendo a que poderá potencializar positivamente o desempenho do grupo.

Uma das autoras que se destaca na perspectiva pluralista é Mary Parket Follet (18681963), segundo a qual as divergências são extremamente importantes como oportunidade de aprendizagem, crescimento e geração de ganhos mútuos, sendo para isso necessário tomar consciência da inevitabilidade do conflito; da percepção individual que cada envolvido tem sobre a mesma situação; e por fim acreditar que vivenciar um conflito corresponde a uma efetiva oportunidade de crescimento (1)

Durante a década de 70, até aos dias de hoje, constata-se uma evolução da teoria do conflito, resultando numa abordagem interacionista de cariz construtivista, segundo a qual se passou a defender que a sua inexistência equivale a monotonia (conformismo e passividade), sendo então o conflito considerado como inevitável e necessário para uma atuação eficaz nas interações humanas.

Nós não devemos ter medo do conflito, porém devemos reconhecer que existe um modo destrutivo e um modo construtivo de proceder em tais momentos. Na diferença em se tratar o conflito pode estar o sinal do saudável, uma profecia do progresso (2)

Também neste sentido, Morton Deutsch (3), psicólogo social, psicanalista e pesquisador de resolução de conflitos, defende que o conflito tem muitas funções positivas, desde logo porque, segundo o mesmo, previne a estagnação e estimula interesses e curiosidades, correspondendo à raiz das mudanças pessoais e sociais por corresponder ao meio através do qual soluções podem ser encontradas. Concluindo o mesmo autor que uma sociedade beneficia do conflito pela sua potencialidade em gerar mudança

Neste sentido, de acordo com a moderna teoria do conflito, positivo ou negativo é o sentimento provocado pela situação de conflito e o comportamento adotado no decorrer de uma situação de discordância, correspondendo o conflito em si a uma situação inevitável. Assim, conflito corresponde a uma divergência que surge da interação entre pessoas ou grupos, que têm interesses, necessidades, valores ou pontos de vista, que são mutuamente percebidos como incompatíveis. 
Sobre esta percepção é ainda importante referir que, por mais útil que seja entender os elementos da realidade objetiva do conflito, é a realidade tal como cada interveniente a vê que origina o conflito, bem como potencializa a construção de soluções.

A responsabilidade de todos é o único caminho para a sobrevivência humana. Não existe nada absoluto, tudo é relativo. Por isso devemos julgar de acordo com as circunstâncias.

A capacidade de mudar de perspectiva pode ser um dos instrumentos mais poderosos e eficazes de que dispomos para nos ajudar a resolver os problemas diários da vida" (4)

Em conclusão, se por um lado podemos afirmar que os conflitos são inevitáveis nos relacionamentos humanos, por outro é possível afirmar a viabilidade de diminuir a sua incidência, minorar os seus efeitos e resolvelos, sem perder amigos, familiares e networking, desenvolvendo maturidade emocional e profissional, escolhendo meios de resolução auto compositivos, como a mediação ou a conciliação técnica (5) "Nenhum problema pode ser resolvido pelo mesmo grau de consciência que o gerou." ${ }^{2}$

Neste sentido, fica reforçada a importância de entender, conhecer e compreender a complexidade do conflito, bem como a importância da sua contextualização, para gerir o mesmo de forma efetiva e eficaz, de acordo com as necessidades em causa, designadamente por meio da Mediação.

\section{Contexto atual da Mediação de Conflitos em Portugal e no Brasil}

Atualmente a Mediação de conflitos encontra-se regulamentada em diversos países, sendo os principais diplomas que a regulamentam, no caso de Portugal a Lei 29/2013 de 19 de abril e do Brasil a Lei 13140 de 26 de junho de 2015 (conjuntamente com o Código de Processo Civil e a Resolução 125 do CNJ com a emenda no 2/2016).

Em ambos os ordenamentos jurídicos - Portugal e Brasil - a Mediação é definida como um processo de resolução de conflitos, realizado por entidades públicas ou privadas, voluntário, em que os mediados procuram alcançar um acordo com o auxílio de um terceiro.

Este terceiro, Mediador, é imparcial e independente, o qual através de procedimentos próprios e técnicas específicas irá auxiliar os mediados em conflito a identificarem

\footnotetext{
2 Albert Einstein, físico teórico alemão, posteriormente radicado nos Estados Unidos, desenvolveu a teoria da relatividade geral, um dos dois pilares da física moderna (ao lado da mecânica quântica). Frases http://kdfrases.com
} 
interesses em comum e necessidades conciliáveis, possibilitando assim a construção conjunta de soluções consensuais.

Neste sentido, de uma forma sumária podemos afirmar que corresponde ao processo consensual de resolução de conflitos, confidencial e voluntário, no qual um terceiro imparcial e independente facilita a negociação entre duas ou mais pessoas e as auxilia a encontrarem e construírem um acordo mutuamente satisfatório.

Igualmente em ambos os ordenamentos o acordo obtido constitui título executivo, podendo assim qualquer um dos mediados, em caso de incumprimento, intentar a respetiva ação executiva.

Uma das particularidades do atual processo judicial brasileiro traduz-se na circunstancia da obrigatoriedade da primeira etapa da mediação, salvo se ambas as partes manifestarem expressamente, desinteresse na composição consensual, nos termos do artigo 334 do novo Código de Processo Civil Brasileiro.

Da experiência tida, na atuação privada e judicial, as etapas do processo nos dois países também se afiguram com características muito semelhantes, verificando-se após o termo de aceitação da mediação, de forma sumária: o relato das histórias, seguido da construção, ampliação e negociação, com fechamento do processo (com ou sem acordo). Sendo também em ambos, o acordo na Mediação uma consequência do trabalho realizado, e não um fim em si mesmo.

Atendendo às afinidades nesta matéria dos ordenamentos jurídicos português e brasileiro, podemos afirmar que em ambos os países a Mediação é um processo consensual, orientado a manter nas pessoas nele interessadas e intervenientes a autonomia e autoria das decisões, tendo como características comuns para além da celeridade, a redução de custos emocionais e financeiros, bem como a possibilidade de preservação dos relacionamentos (independentemente do grau de intimidade ou proximidade).

Cumpre afirmar que o processo de mediação ele corresponde a um instrumento de trabalho para relações continuadas no tempo, onde se verifique uma de quatro intenções em relação ao relacionamento: manter; melhorar; não deteriorar; iniciar.

Neste sentido, impõe-se como requisitos prévios para a sua escolha a existência de vontade de negocial, e em consequência a possibilidade de ter um objeto negociável (que 
não envolva a necessidade de questões de prova), onde apesar das divergências, de posições e motivações individuais, seja possível compatibilizar interesses e necessidades.

Sobre as particularidades, semelhanças e diferenças entre os dois ordenamentos, entendemos deixar para outro momento o aprofundamento das questões existentes, para nos centrarmos no tema escolhido para presente artigo.

\section{Mediação de conflitos na área da saúde}

Todas as questões que envolvem múltiplas partes são complexas e tendencialmente conflituosas, razão pela qual os processos dialógicos consensuais e colaborativos permitem alcançar benefícios mútuos, de forma célere, mais económica e com menor desgaste.

Alguns dos resultados manifestados por quem já vivenciou a sua utilização traduzemse na circunstância de que, para além de prevenir a formação de conflitos e a sua reincidência, a Mediação possibilita uma melhor fluidez na comunicação e potencializa claras melhorias no relacionamento intergrupal e interpessoal.

As áreas de atuação dos meios extrajudiciais de resolução de litígios, em particular a Mediação e a Conciliação técnica, têm se diversificado, sendo atualmente bastante vasta. Assim, além das áreas tradicionais de família, a mediação tem gerado bons resultados em outras áreas como a organizacional (instituições e empresas), internacional, político-social, comunitária, administrativa e escolar. Acresce que, uma das áreas em que a atuação da mediação, como método de resolução de conflitos, tem se apresentado como altamente eficaz e eficiente é a área da saúde.

Trata-se de um segmento no qual se impõe o interesse e a necessidade de facilitar o diálogo entre as múltiplas partes envolvidas: pacientes, família, médicos, assistentes, técnicos, companhias seguradoras, prestadores de serviços, dentre outros como é o caso do hospital ${ }^{3}$.

Acresce que a tecnologia na saúde tem avançado exponencialmente implicando um constante investimento de atualização das estruturas e infraestruturas que oferecem

\footnotetext{
${ }^{3}$ Um hospital poderá ter 3.000 trabalhadores, onde dos $50 \%$ de trabalhadores da área do conhecimento podem ter mais de 30 tipos de áreas profissionais, com a aplicação de regras, exigências e qualificações diversas. No entanto, por regra poucos desses trabalhadores exercem a sua atividade de forma autónoma ou esperam que os demais exerçam a sua autonomia.
} 
serviços de especialidade e tratamentos, implicando um aperfeiçoamento dos profissionais que atuam com técnicas, e aplicam esses conhecimentos em pessoas com patologias de diferentes gravidades.

Sem qualquer margem para dúvidas, portanto, o contexto da área da saúde, quer pela existência de múltiplas partes envolvidas, com diferentes necessidades, quer pelo próprio ambiente e cenários onde ocorrem, quer pelas particularidades éticas e negociais, potencializa o surgimento de situações conflitantes, acrescido das necessidades da sua resolução de forma consensual, nomeadamente atendendo ao desgaste das relações."O hospital é a mais complexa organização humana já concebida" (6)

Levando em consideração que cada envolvido no conflito terá um discurso diferenciado (discurso técnico, discurso emocional e discurso financeiro), um terceiro facilitador com as características do mediador, tem condições de potencializar, de forma notória, a possibilidade de diálogo, a gestão do conflito e a construção de soluções que possam ser acolhidas por todos os intervenientes, satisfazendo os interesses e necessidades dos envolvidos.

Dentre outros fatores, o sucesso da mediação e da conciliação técnica, como métodos que podem ser efetivamente escolhidos pela área da saúde para gerir e resolver conflitos $^{4}$, resulta 0 fato de que grande parte das situações pressupõem questões relacionais implícitas, que não são normalmente resolvidas em um processo comum (judicial ou arbitragem).

Além disso, o diálogo passa a fazer parte do tratamento e da prestação de serviços oferecida ao paciente e à sua família, potencializando assim a qualidade do serviço prestado.

Em uma ótica preventiva do conflito ou em uma ótica de resolução em tempo real just in time resolution, os profissionais da área da saúde têm todo o interesse e necessidade de conhecer e desenvolver técnicas que facilitem o seu trabalho diário, minimizando, assim, o número de situações de conflito que têm de gerenciar e resolver. Com isso, ganha-se, entre outros benefícios, a pacificação e satisfação, bem como a salvaguarda das

\footnotetext{
${ }^{4}$ Para verificação de alguns modelos já existentes e em funcionamento acesse: Health Care Mediations collaborative solutions for Clinical Conflict (www.healthcaremediations.com); Program on health care negotiation and conflict resolution (www.hsph.harvard.edu/hcncr/); American Health Lawyers Association (www.healthlawyers.org)
} 
expetativas no futuro e redução do tempo gasto com questões que são estranhas à sua área de atuação: a saúde.

\section{Multiplicidade de conflitos e intervenientes na área da saúde}

Conversar sobre, saúde, relações com direitos e deveres que se criam, conflitos que daí decorrem e procedimento para os resolver, impõe também proceder a uma prévia separação de possíveis situações com necessidade de resolução, designadamente, por um lado os casos relativos à prestação de serviços e cuidados de saúde, como internação, execução de procedimentos cirúrgicos, exames e consultas. E por outro, questões relacionadas com tratamentos e medicamentos.

Esta divisão permite, nomeadamente, separar e identificar os diversos sujeitos intervenientes na multiplicidade de conflitos que encontramos nesta área específica do Direito. Assim, podemos colocar, a título exemplificativo, em termos de sujeitos intervenientes: pacientes, hospitais, clinicas, entes públicos, seguradoras, pessoas jurídicas de direito público, Estado, Município, entre outros.

A descrição apresentada visa permitir identificar os conflitos que mais frequentemente buscam encontrar uma solução por via da esfera do judiciário, por forma a que, respeitando o princípio da separação de poderes, verificar a disponibilidade de tratamento adequado a esta área, extraordinariamente sensível dos direitos fundamentais, que é a Saúde, possibilitando igualmente uma maior eficiência do judiciário.

A complexidade das relações na área da saúde são também verificáveis na diversidade de diálogo entre as múltiplas partes que se relacionam, identificando nos conflitos mais comuns, pelo menos, três tipos de linguagens, de acordo com os intervenientes:

$\infty$ Médicos; Staff - linguagem ética e técnica

$\infty$ Famílias; Pacientes; Acompanhantes - linguagem emocional

$\infty$ Empresas; Operadoras e Seguradoras - linguagem financeira

Atendendo a esta particularidade de múltiplas partes com diálogos distintos, atendendo a funções e objetivos absolutamente diversos, resulta verificado que na grande maioria dos processos judiciais e arbitrais, na área da saúde, as questões relacionais são citadas e implicadas no conflito, não sendo esta situação resolvida pela litigância. Neste 
sentido, a intervenção de um terceiro facilitador que consiga potencializar a comunicação através do entendimento dos diversos discursos utilizados (ética; técnica; emocional e financeira) potencializa o consenso e a construção de soluções que para além da situação resolvam definitivamente o problema.

Neste ponto, é importante passar a considerar que o diálogo deve ser parte do tratamento e prestação do serviço dado. Assim, importa referir, relativamente ao paciente e seu acompanhante, a grande maioria dos conflitos na área da saúde referem-se a uma necessidade de compreensão do que aconteceu (pelo não domínio de questões técnicas); um reconhecimento ou responsabilidade sobre o acontecimento (financeiro); confiança de não repetição com mais ninguém (emocional).

Das experiências tidas com casos de mediação na área da saúde, entre pacientes e profissionais, é possível referir que na sua esmagadora maioria, em casos de erro médico, encontramos as seguintes constatações:

$\infty$ Ambos sofrem emoções após uma situação;

$\infty$ Pacientes necessitam de apoio emocional e desculpas do profissional;

$\infty$ Profissionais querem se desculpar, mas temem consequências da admissão legal de culpa

$\infty$ Revelação de erro e pedido de desculpas frequentemente diminui emoções negativas e resulta em desistência de acionar judiciário ou arbitragem

$\infty$ Revelação de erro que não cause danos aumenta o nível de confiança na relação.

\section{Conclusões}

Atendendo às múltiplas partes envolvidas, bem como às particularidades das suas necessidades individuais, com possíveis múltiplos cenários de negociação, resulta verificado a enorme vantagem em custos e benefícios na utilização do diálogo e construção de consenso, em particular da Mediação como procedimento de facilitação de diálogos na área da saúde, onde já é pressuposto a existência de um desgaste emocional pela questão de saúde vivenciada.

O principal objetivo da proposta de projetos de mediação na área da saúde visa auxiliar os pacientes e acompanhantes a se sentirem escutados, bem como a encontrar 
soluções rápidas e justas que reduzam ou minimizem o desgaste e sofrimento emocional já característico de quem tem está a viver questões relacionadas com a saúde.

É assim necessário continuar a formar e certificar mediadores, mas também a advocacia para atuar de forma colaborativa em procedimentos de mediação, o que tem vindo a ser realizado no Brasil, com o apoio incondicional e interessado da Ordem dos Advogados do Brasil, em particular de Minas Gerais, entre outros parceiros, tendo já formados para atuarem de forma profissional, numa advocacia colaborativa e consensual, mais de 150 profissionais da advocacia mineira, tendo como expetativa continuar a fazer crescer este número.

No caso em particular da área da saúde é necessário formar profissionais para que saibam conversar com pacientes e familiares, designadamente, sobre danos, viabilizando uma comunicação efetiva por meio da utilização de técnicas de facilitação, negociação e mediação.

Como complemento conclusivo, importa realçar a importância de atuar numa abordagem programática de prevenção e gestão do conflito, sem esquecer o necessário alinhamento e colaboração de todos os intervenientes com a comunidade legal fiscalizadora.

\section{Referências}

1. Follett, MP. Profeta do gerenciamento. Rio de Janeiro: Qualitymark, 1997.

2. Hampton, DR. Administração: comportamento organizacional. São Paulo: McGraw-Hill, 1991.

3. Deutsch, M. The Resolution of Conflicts, Yale University Press, 1973.

4. Lama, D e Cutler, HC., A Arte da Felicidade, Livraria Martins Fontes Editora, São Paulo, 1. ․ Edição, 2000.

5. Nascimento, DMM. Julgados de paz e conciliação técnica: sua importância no paradigma da Justiça Restaurativa. Disponível em

http://repositorio.ulusiada.pt/bitstream/11067/716/1/md_dulce_nascimento_dissertacao.pdf Acesso em 4 abr 2016. 
Cuadernos Iberomericanos

de Derecho Sanitario

6. Drucker, P; Malferrarl, C. Inovação e espírito empreendedor. Editora Cengage Learning Editores, 1999.

Recebido em: 18/9/2016 Aprovado em: 29/9/2016

\section{Como citar este artigo:}

Nascimento D. Mediação de Conflitos na Área da Saúde: experiência portuguesa e brasileira. Revista Cadernos Ibero-Americanos de Direito Sanitário. 2016 jul./set, 5(3):201-211. 